\title{
STUDIES ON THE ANTIOXIDANT ACTIVITY OF Costus igneus LEAF EXTRACT
}

\author{
NIMMY CHACKO ${ }^{1}$, C.S SHASTRY², PRERANA SHETTY ${ }^{3}$
}

1,2: Department of Pharmacology , 3: Department of pharmaceutical Chemistry, Nitte Gulabi Shetty memorial Institute of Pharmaceutical sciences, Nitte Deemed to be University, Mangalore, 575 018, India.

Key words: Costus igneus, Radical scavenging activity, phenol content

Correspondence:

Nimmy Chacko, M.Pharm, Ph.D

Department of Pharmacology, Nitte Gulabi Shetty memorial Institute of Pharmaceutical sciences, Nitte Deemed to be University, Mangalore, 575 018, India.

Received: 27 December 2017,

Revised: 12 March 2018

Accepted: 25 March 2018,

Available online: 15 September 2018

\begin{abstract}
Plan: The antioxidant activity studies of the extract of Costus igneus leaves

Preface: Costus igneus commonly known as fiery costus or Spiral flag is a species of herbaceous plant. It is claimed to help build up insulin in human body and is sometimes referred to as insulin plant. Insulin plant Costus igneus (Fam: Zingiberaceae) is a tropical evergreen shrub with large, smooth, dark green leaves. The Costus igneus is valued mainly for its tonic, stimulant and antiseptic properties. It is said to be aphrodisiac and to be able to prevent the hair turning grey. It's root is anodyne, antibacterial, antispasmodic, aphrodisiac, carminative, stimulant, stomachic, tonic and vermifuge.

Methodology: In the present study the antioxidant activity of the leaf extract was studied using four methods viz. DPPH assay, reducing power assay, superoxide radical scavenging assay and Folin-ciocalteu assay.

Outcome: The studies have proved that extract possess antioxidant activity. In reducing power assay, the plant extract showed $75.43 \%$ increase in reducing power compared to Ascorbic acid which showed 91.94\%, at a concentration of $16 \mu \mathrm{g} / \mathrm{ml}$. In DPPH assay, plant extract produced $71.85 \%$ DPPH scavenging activity, compared to Ascorbic acid which produced $84.47 \%$ at a concentration of $160 \mu \mathrm{g} / \mathrm{ml}$. In super oxide scavenging activity, the plant extract produced $68.19 \%$ radical scavenging activity compared to the standard which showed $79.78 \%$ at a concentration of $800 \mu \mathrm{g} / \mathrm{ml}$. The IC50 was found to be177 and 367 $\mu \mathrm{g} / \mathrm{ml}$ of the standard and plant extract respectively.
\end{abstract}

\section{INTRODUCTION}

Strong epidemiological evidence suggests that regular consumption of fruits and vegetables can reduce cancer risk. Towards this end, the past several decades have been an explosion of research focused on the role played by antioxidant nutrients in human cancer. Phytochemicals in common fruits and vegetables can have complementary and overlapping mechanisms of action, including of gene expression in cell proliferation, cell differentiation, oncogenes and tumour suppressor genes; induction of cell-cycle arrest and apoptosis, modulation of enzyme activities in detoxification, oxidation and reduction; stimulation of the immune system; regulation of hormone metabolism; as well as antibacterial and antiviral effects ${ }^{1}$. 
Naturally occurring antioxidants like ascorbic acid, carotenoids and phenolic compounds are highly effective biologically ${ }^{2}$. They are act by inhibiting lipid peroxidation (by inactivating lipoxygenase), scavenge free radicals and active oxygen species by propagating a reaction cycle and chelate heavy metal ions. ${ }^{3}$

Commonly Costus igneus is known as fiery costus or Spiral flag or insulin plant, and in literature, it is claimed to increase the levels of insulin ${ }^{4}$. C. igneus / C. pictus (Family: Zingiberaceae) is a tropical evergreen shrub with large, smooth, dark green leaves and grown in America and India due to its medicinal value. It is now accepted and used widely as an Ayurvedic medicinal herb. Allopathic doctors too recommend it for bringing blood sugar levels under control. ${ }^{5}$

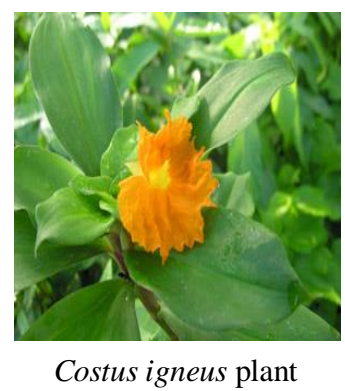

In traditional medicine $C$. igneus is appreciated mainly for its tonic, stimulant, antiseptic, anodyne, antibacterial, antispasmodic, aphrodisiac, carminative, stimulant, stomachic, tonic and vermifuge properties $^{4,5}$. Therefore, the main objective of the present study was to evaluate the antioxidant activity of the leaves of this plant.

\section{MATERIALS AND METHODS}

\subsection{Plant material}

Fresh leaves of the plant were collected from Puttur, Karnataka and authenticated by Dr. Noeline J. Pinto, Head of Botany Dept., St.Agnes College, at Mangalore. The Leaves were dried in shade and powdered for extraction.

\subsection{Preparation of ethanolic extract}

The leaves of Costus igneus were collected from Puttur, Karnataka, India during June 2009. The shade dried powdered leaves $(5 \mathrm{~kg})$ were soaked in ethanol $(95 \%)$ and kept aside for four days. After four days the ethanol layer was decanted off. The process was repeated four times. The solvent of total extract was distilled off and concentrate was evaporated on a water bath to a syrupy consistency and evaporated to dryness. The percentage yield was $0.6 \%$.

\subsection{Evaluation of Antioxidant activity by in-vitro Techniques:}

\subsubsection{Reducing power assay ${ }^{6}$}

Different aliquots of the extracts and ascorbic acid were mixed with Phosphate buffer $(2.5 \mathrm{ml})$ and potassium ferricyanide $(2.5 \mathrm{ml})$, the mixture was incubated at $50^{\circ} \mathrm{C}$ for 20 minute. TCA $(2.5 \mathrm{ml})$ was added and centrifuged at $6000 \mathrm{rpm}$ for 10 minute. To the supernatant added $0.5 \mathrm{ml}$ of ferric chloride. Absorbance was measured at $700 \mathrm{~nm}$ using Jasco spectrophotometer. A blank was prepared without adding extract. The experiment was repeated in triplicates and results were tabulated. Table 3 \& Fig. 2. 


\subsubsection{DPPH assay $^{7}$}

Different aliquots of extracts and standard solution were taken in different test tubes. To these $5 \mathrm{ml}$ methanolic solution of 1, 1-diphenyl-2-picryl hydrazyl (DPPH) was added. The blanks were prepared as above without extract. The readings were noted at $515 \mathrm{~nm}$ using Jasco spectrophotometer, at 0,1 , 15 and 30 minutes (Table 1\& Fig.1). The changes of absorbance of samples were measured and scavenging activity was expressed as:

\section{$\%$ Radical scavenging $=\underline{\text { Control Absorbance }- \text { Sample Absorbance }} \times 100$}

Control Absorbance

\subsubsection{Superoxide radical scavenging activity ${ }^{8}$}

To different aliquots of sample was added $1 \mathrm{ml}$ of sodium carbonate, $0.4 \mathrm{ml}$ of NBT and $0.2 \mathrm{ml}$ of EDTA. The zero minute reading is taken at $560 \mathrm{~nm}$. To the above added $0.4 \mathrm{ml}$ of hydroxylamine hydrochloride, incubated at $25^{\circ} \mathrm{C}$ for 15 minute. The final reading is taken at $560 \mathrm{~nm}$ again. The difference in the initial and final reading is taken for each sample, keeping suitable control samples. Readings are taken in triplicates. Table 2 and Fig.2.

$$
\% \text { Superoxide scavenging Activity }=1-\frac{\text { Difference in the absorbance of sample } \times 100}{\text { Difference in the absorbance of blank }}
$$

\subsubsection{Estimation of total Phenol content ${ }^{9}$}

The extract samples $(0.5 \mathrm{ml}$ of different dilutions) were mixed with Folin Ciocalteu reagent $(5 \mathrm{ml}$, 1:10 diluted with distilled water) for $5 \mathrm{~min}$ and aqueous $\mathrm{Na}_{2} \mathrm{CO}_{3}(4 \mathrm{ml}, 1 \mathrm{M})$ were then added. The mixture was allowed to stand for $15 \mathrm{~min}$ and the phenols were determined by colorimetric method at $765 \mathrm{~nm}$. The standard curve was prepared by $0,50,100,150,200$, and $250 \mathrm{mg} / \mathrm{ml}$ solutions of Gallic acid in methanol: water $(50: 50, \mathrm{v} / \mathrm{v})$. Total phenol values are expressed in terms of Gallic acid equivalent ( $\mathrm{mg} / \mathrm{g}$ of dry mass), which is a common reference compound.

\subsubsection{Determination of total phenol content by Folin-Ciocalteu method}

The total phenol content was found to be $78.89 \pm 3.94 \mathrm{mg} / \mathrm{g}$ dry mass GAE.

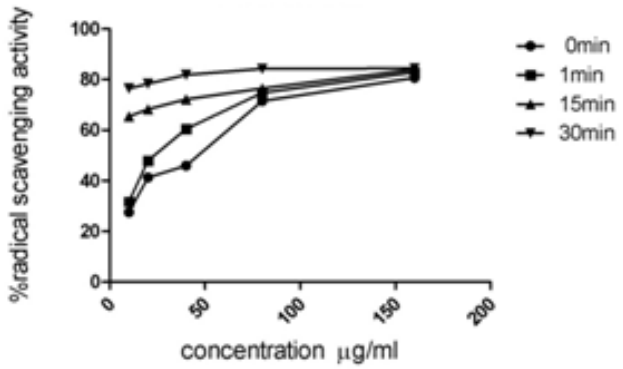

Fig.1: Ascorbic acid assay

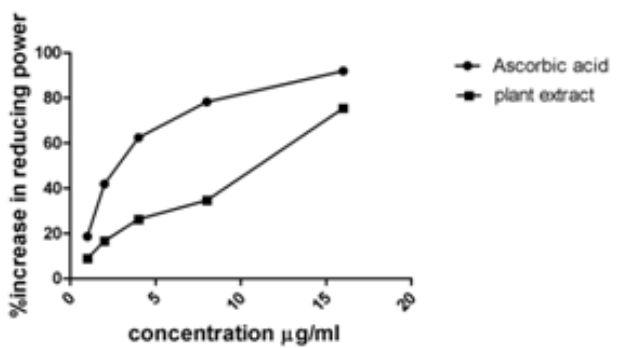

Fig.2: Reducing power assay 
Table 1: In vitro Antioxidant Activity: DPPH Assay

\begin{tabular}{|c|c|c|c|c|c|}
\hline \multirow[t]{2}{*}{ sample } & \multirow[t]{2}{*}{ Conc. $(\mu \mathrm{g} / \mathrm{ml})$} & \multicolumn{4}{|c|}{ \% DPPH radical scavenging activity } \\
\hline & & $0 \mathrm{~min}$ & $1 \mathrm{~min}$ & $15 \mathrm{~min}$ & $30 \mathrm{~min}$ \\
\hline \multirow[t]{5}{*}{ Acsorbic acid } & 10 & $27.53 \pm 0.01$ & $31.72 \pm 0.01$ & $65.42 \pm$ & $76.42 \pm 0.34$ \\
\hline & 20 & $41.25 \pm 0.009$ & $47.94 \pm 0.002$ & $68.32 \pm 0.001$ & $78.36 \pm 0.005$ \\
\hline & 40 & $45.96 \pm 0.021$ & $60.46 \pm 0.009$ & $72.20 \pm 0.023$ & $81.85 \pm 0.002$ \\
\hline & 80 & $71.53 \pm 0.032$ & $74.78 \pm 0.030$ & $76.54 \pm 0.024$ & $84.32 \pm 0.004$ \\
\hline & 160 & $80.69 \pm 0.002$ & $82.85 \pm 0.006$ & $84.05 \pm 0.092$ & $84.47 \pm 0.002$ \\
\hline \multirow[t]{5}{*}{ Plant extract } & 10 & $18.29 \pm 0.023$ & $22.01 \pm 0.033$ & $61.22 \pm 0.001$ & $71.02 \pm 0.009$ \\
\hline & 20 & $29.25 \pm 0.003$ & $36.80 \pm 0.050$ & $63.15 \pm 0.025$ & $71.25 \pm 0.001$ \\
\hline & 40 & $37.64 \pm 0.0057$ & $50.01 \pm 0.006$ & $66.3 \pm 0.006$ & $71.58 \pm 0.020$ \\
\hline & 80 & $49.75 \pm 0.006$ & $53.25 \pm 0.003$ & $70.89 \pm 0.010$ & $71.63 \pm 0.023$ \\
\hline & 160 & $60.80 \pm 0.031$ & $67.77 \pm 0.004$ & $70.16 \pm 0.007$ & $71.85 \pm 0.004$ \\
\hline
\end{tabular}

All values are expressed as mean \pm SEM, $\mathrm{p}<0.05$ compared to standard. The data was analyzed by one way analysis of variance (ANOVA) followed by Post hoc Dunnett's test by using the software Graph pad prism 5.

Table 2: Super oxide scavenging assay

\begin{tabular}{cccc}
\hline \multirow{2}{*}{ Sample } & Concentration $\mu \mathrm{g} / \mathrm{ml}$ & Superoxide Radical scavenging activity $( \pm \mathrm{SEM})$ & IC50 $(\mu \mathrm{g} / \mathrm{ml})$ \\
\hline \multirow{3}{*}{ Gallic Acid } & 100 & $35.67 \pm 0.004$ \\
& 200 & $52.31 \pm 0.035$ \\
& 400 & $63.78 \pm 0.006$ & 177 \\
& 600 & $71.22 \pm 0.021$ & 367 \\
Plant extract & 100 & $79.78 \pm 0.004$ & $19.05 \pm 0.013$ \\
& 200 & $41.63 \pm 0.045$ & $50.44 \pm 0.005$ \\
\end{tabular}

All values are expressed as mean \pm SEM, $p<0.05$ compared to standard. The data was analyzed by one way analysis of variance (ANOVA) followed by Post hoc Dunnett's test by using the software Graph pad prism 5 .

Table 3: Reducing power assay

\begin{tabular}{cccc}
\hline Tested Material & Concentrations $(\mu \mathrm{g} / \mathrm{ml})$ & Reducing Power in $\%( \pm \mathrm{SEM})$ & $\mathrm{IC}_{50}(\mu \mathrm{g} / \mathrm{ml})$ \\
\hline & 1 & $18.64+0.011$ & \\
Ascorbic acid & 2 & $41.89 \pm 0.012$ & 2.25 \\
& 4 & $62.48 \pm 0.002$ & \\
& 8 & $78.28 \pm 0.004$ & 4.40 \\
\hline & 16 & $91.94 \pm 0.013$ & \\
\hline
\end{tabular}




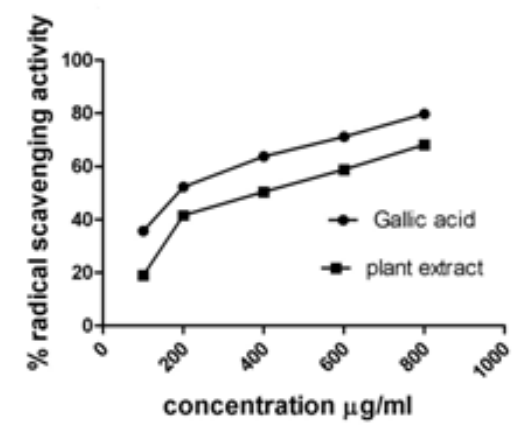

Fig.3: Super oxide scavenging assay

\section{RESULTS}

\subsection{Reducing power assay}

The reductive capabilities of the alcoholic extracts of Costus igneus were compared with ascorbic acid for the reduction of the $\mathrm{Fe} 3+-\mathrm{Fe} 2+$ transformation. The reducing capacity of a compound may serve as a significant indicator of its potential antioxidant activity.

In this method the plant extract showed $75.43 \%$ increase in reducing power compared to Ascorbic acid which showed $91.94 \%$, at a concentration of $16 \mu \mathrm{g} / \mathrm{ml}$. The antioxidant activity may be attributed to various mechanisms, among which are prevention of chain initiation, binding of transition metal ion catalysts, decomposition of peroxides, prevention of continued hydrogen abstraction, reductive capacity and radical scavenging antioxidant activity. The reducing power of alcoholic extract of Costus igneus increased with increasing amount of sample.

\subsection{DPPH assay}

The 1, 1-diphenyl-2-picryl hydrazyl (DPPH) radical widely used as the model system to investigate the scavenging activities of several natural compounds such as phenols or crude mixtures such as the ethanolic extract of plants. DPPH radical is scavenged by antioxidants through the donation of proton forming the reduced DPPH. The color changes from purple to yellow after reduction, which can be quantified by its decrease of absorbance at wavelength $517 \mathrm{~nm}$. Radical scavenging activity increased with increasing percentage of the free radical inhibition.

DPPH is a relatively stable radical. The assay is based on the measurement of the scavenging ability of antioxidants towards the stable radical DPPH which reacts with suitable reducing agent. The electrons become paired off and solution loses color stoichiometrically depending on the number of electrons taken up. DPPH was used to determine the proton radical scavenging action of alcoholic extract of Costus igneus, because it possess a proton free radical and shows a characteristic absorbance at $517 \mathrm{~nm}$. In this method, plant extract produced $71.85 \%$ DPPH scavenging activity, compared to Ascorbic acid which produced $84.47 \%$ at a concentration of $160 \mu \mathrm{g} / \mathrm{ml}$. From the present results, it may be postulated that Costus igneus has the potential to reduce the radical to corresponding hydrazine when it reacts with hydrogen donors in antioxidant principles. 


\subsection{Superoxide radical scavenging activity}

Superoxides are produced from molecular oxygen due to oxidative enzymes of body as well as via non-enzymatic reaction such as auto oxidation of hydroxylamine hydrochloride. The scavenging activity towards the superoxide radical (O2.-) is measured in terms of inhibition of generation of $\mathrm{O} 2$. In the present study, superoxide radical reduces NBT to a formosan that is measured at $560 \mathrm{~nm}$. In this method the plant extract produced $68.19 \%$ radical scavenging activity compared to the standard which showed $79.78 \%$ at a concentration of $800 \mu \mathrm{g} / \mathrm{ml}$. The IC50 was found to be177 and $367 \mu \mathrm{g} / \mathrm{ml}$ of the standard and plant extract respectively. The result shows that alcoholic extract of Costus igneus has potent radical scavenging activity with increasing percentage inhibition. The probable mechanism of scavenging the superoxide anions may be due to the inhibitory effect of the extract towards generation of superoxides in the in vitro reaction mixture.

\subsection{Determination of total phenol content by Folin-Ciocalteu method}

The F-C assay has for many years been used as a measure of total phenolics in natural product, but mechanism of action is oxidation/ reduction reaction and as such considered another antioxidant method.

It is obvious that the total phenolic content measured by the Folin- Ciocalteu procedure does not give a full picture of the quantity or quality of the phenolic constituents in the extracts. In addition, there may be some interference rising from other chemical components present in the extract, such as sugars or ascorbic acid ${ }^{13}$. Similarly it must be noted that the efficiency of antioxidants depends strongly on the oxidation conditions and lipid substrate.

\section{DISCUSSION}

Pathology of many diseases such as inflammatory condition, cancer, diabetes and aging has been attributed to oxidative stress. Free radicals induced by peroxidation implicated in several pathological conditions such as atherosclerosis, ischemia, liver disorder, metal toxicity and pesticide toxicity.. Reactive oxygen species (ROS) such as superoxide anions (O2.-), hydroxyl radicals (OH.) and nitric oxide (NO) damage enzymes and important cellular components causing injury through covalent binding and lipid peroxidation. Antioxidants may offer protection against oxidative stress by scavenging the free radicals, inhibiting the lipid peroxidation and by other mechanisms and thus prevent disease. Foods rich in antioxidants play an important role in the prevention of cardiovascular disease, cancer, neurodegenerative diseases, inflammation and problems caused by cell and cutaneous aging.

The results from the preliminary phytochemical screening showed presence of phenolic compounds, Flavonoides and tannins as phytochemical constituents which may be responsible for the antioxidant properties. In general, polyphenolic compounds are widely distributed in plant kingdom and possess strong antioxidant properties. ${ }^{10}$ Phenolic compounds are found in both edible and non edible plants, and known to have multiple biological effects, including antioxidant activity. Flavonoides and other plant phenolics, such as phenolic acids, stilbenes, tannins, lignans, and lignin, are especially common in leaves, flowering tissues, and woody parts such as stems and barks ${ }^{11}$. 
They are important in the plant for normal growth development and defence against infection and injury. Flavonoides also partly provide plant colours present in flowers, fruits, and leaves. They generally occur as glycosylated derivates in plants, although conjugation with inorganic sulfate or organic acid is also known ${ }^{12}$.

\section{Acknowledgments}

The authors are thankful to Nitte Gulabi Shetty memorial institute of Pharmaceutical sciences for providing the necessary facilities for carrying out the work.

\section{References}

1. Sun J, Chu YF, Wu X, Liu RH. Antioxidant and antiproliferative activities of fruits. J.Agric.FoodChem Chem 2002; 50:7449-7454.CrossRef, PMid: 12452674.

2. Duh PD, Tu YY, Yen GC . Antioxidant activity of water extract of harn jyur (Chyrsanthemum morifolium Ramat). LWT-Food Sci.Technol.1999; 32: 269-277.

3. Raja Sudarajan N, Ahamad H, Kumar V (2006). Cytisus scoparius Link-A natural antioxidant.2006; 6: $1-7$.

4. Kerala Ayurvedics.com [home page on the Internet], Trivandrum: c2007-2009 [updated 2009 March 23; cited 2009 June 07]. Insulin Plant (Costus igneus) Ayurvedic Medicinal Herbs; Available from: www.keralaayurvedics.com/herbs-plants/insulin-plant-costus-igneus-ayurvedic-medicinal-herbs.

5. DiabetoValens.com [home page on the Internet]. Hyderabad; c2007-2009 [updated 2004 July 01; cited 2009 June 07]. 'Insulin plant' turning a daily munching diet for diabetics' (Source: Kerala Agricultural University); Available from: http://my.diabetovalens.com/diab_update/latestnews.asp?newsid=1245

6. Oyaizu, M.. Studies on products of browning reactions: antioxidative properties of products of browning reaction prepared from glucosamine. JPN. J. Nutr 1986; 44:307-315.CrossRef.

7. Bracca A, Tommasi ND, Bari LD, Pizza C, Politi M, and Morelli I Antioxidant principles from Bauhinia terapotensis. Journal of Natural Products 2001; 64: 892-895.CrossRef

8. Rathee J.S., Hassarajani S.A., Chattopadhyay S. - Antioxidant activity of Mammea longifolia bud extracts. Food Chemistry 2006;99: 436 - 443

9. Ebrahimzadeh MA, Pourmorad F and Bekhradnia AR. Iron chelating activity screening, phenol and flavonoid content of some medicinal plants from Iran. Afr. J. Biotechnol 2008; 32: 43-49. CrossRef

10. Oscar MM, Yaned MC, Diana CB, Jaime N. Antioxidant activity of twenty five plants from Colombian biodiversity. Mem Inst Oswaldo cruz, Rio de Janeiro 2007; 102(5):631-34. CrossRef

11. Larson R. A. The antioxidants of higher plants. Phytochemistry 1988; 27: 969-978.

12. Heldt, W. Plant biochemistry and molecular biology; Oxford University Press: Oxford, 1997. Available from http://www.exrx.net/nutrition/antioxidants/introduction/html.

13. Singleton, V. L.; Rossi, J. A. Colorimetry of total phenolics with phosphomolybdic-phosphotungstic acid reagents. Am. J.Enol. Vitic. 1965;16: 144-158 